\title{
Comunicação
}

\section{Qualidade de nectarinas produzidas em região de clima subtropical ${ }^{1}$}

\author{
Rosana Gonçalves Pires Matias ${ }^{2}$, Danielle Fabíola Pereira da Silva ${ }^{2 *}$, José Osmar da Costa e Silva ${ }^{2}$, \\ João Alison Alves Oliveira², João Paulo Gava Cremasco², Cláudio Horst Bruckner ${ }^{2}$
}

http://dx.doi.org/10.1590/0034-737X201562060016

\section{RESUMO}

Os frutos de nectarineiras geralmente apresentam tamanho pequeno, polpa firme, aroma e sabor bem acentuados. O conhecimento dos cultivares disponíveis, em relação a sua qualidade, bem como a sua adaptação aos locais de cultivo é extremamente importante, por possibilitar a escolha dos materiais com melhor potencial de mercado. Assim, este trabalho teve como objetivo avaliar os cultivares de nectarineira 'Josefina' e 'Rubro- Sol', cultivados sob condições de clima subtropical, em Viçosa, MG. Os experimentos foram realizados na Universidade Federal de Viçosa durante três safras e conduzidos em esquema de parcelas subdivididas, dentro do delineamento inteiramente casualizado. Foram colhidos 30 frutos de cada cultivar e avaliadas as características massa de fruto, diâmetros longitudinal e transversal, firmeza, teor de sólidos solúveis, acidez titulável e teores de ácido ascórbico e de carotenoides. Verificaram-se diferenças significativas entre as médias dos anos de avaliação quanto à firmeza e aos teores de ácido ascórbico e de carotenoides. O cultivar 'Rubro- Sol' destacou-se pela maior firmeza da polpa e o 'Josefina' pelo maior teor de sólidos solúveis e menor acidez titulável, com frutos mais doces.

Palavras-chave: Prunus persica var. nucipersica, 'Josefina', 'Rubro- Sol', pós-colheita.

\section{ABSTRACT}

\section{Quality of nectarines produced in a subtropical climate region}

Nectarines usually have small, firm flesh, good aroma and marked flavor. Knowledge on available cultivars in relation to quality as well as their adaptation to areas ofcultivation are extremely important as they allow the choice of materials with better market potential. Thus, the present study aimed to evaluate the nectarine cultivars 'Josefina' and 'Rubro- Sol' grown under subtropical conditions in Viçosa-MG. The experiments were carried out at the Universidade Federal de Viçosa for three seasons and conducted in split plots within the randomized design. Thirty fruits of each cultivar were harvested and the characteristics fruit weight, longitudinal and transverse diameters, firmness, soluble solids, titratable acidity and ascorbic acid contents and carotenoids were evaluated. There were significant differences between the means of years of evaluation for firmness and levels of ascorbic acid and carotenoids. The cultivar 'Rubro-sol' stood out for greater firmness and 'Josefina' by higher soluble solids and lower titratable acidity, with the sweetest fruits.

Key words: Prunus persica var. nucipersica, 'Josefina', 'Rubro- Sol', post-harvest.

\footnotetext{
Submetido em 07/11/2014 e aprovado em 05/08/2015.

${ }^{1}$ Apoio financeiro: CAPES, CNPq e FAPEMIG.

22Universidade Federal de Viçosa, Departamento de Fitotecnia, Viçosa, Minas Gerais, Brasil. rosana.pires@ufv.br; danieele@ufv.br; joksilva7@yahoo.com.br; joao.alison@yahoo.com.br; cremasco_7@hotmail.com; bruckner@ufv.br

*Autora para correspondência: danieele@ufv.br
} 


\section{INTRODUÇÃO}

A nectarina (Prunus persica var. nucipersica), fruto de origem chinesa, é um tipo de pêssego com epiderme desprovida de pêlos, tamanho pequeno, polpa firme, aroma e sabor bem acentuados, é resultante de uma mutação genética do pêssego (Prunus persica var. vulgaris), surgida há muitos anos, que apresenta epiderme glabra e geralmente muito colorida (Leonel $e t$ al., 2014). Apenas um gene (G/g, pubescente/glabra) diferencia as variedades botânicas vulgaris e nucipersica, entretanto, existem vários efeitos pleiotrópicos sobre os caracteres de fruto associados a esse gene (Byrne $e t$ al., 2012).

De forma geral, os frutos geralmente apresentam tamanho pequeno, polpa firme, aroma e sabor bem acentuados (Raseira et al., 2014). É uma fruteira de clima temperado exigente em frio hibernal para superação da dormência. No entanto, a região sudeste, em locais de clima ameno, apresenta boas condições para a exploração econômica de fruteiras de clima temperado, por causa, principalmente, da elevada altitude (Ramos \& Leonel, 2008) e da utilização de cultivares com baixa exigência em frio. Em consequência do melhoramento genético, a expansão da fruticultura de clima temperado vem avançando, progressivamente, com sucesso econômico (Leonel et al., 2011). De acordo com Raseira et al. (2014), um dos objetivos importantes do melhoramento genético das prunoideas, para regiões do Brasil é a sua adaptação a condições de inverno ameno, como a baixa necessidade de acúmulo de frio para quebra de dormência de gemas. No caso da nectarina, um aspecto promissor do melhoramento de frutos é a existência de herança qualitativa de algumas características, como polpa branca, a forma achatada e o fruto doce.

A nectarina vem despontando como uma estratégia para aumentar a disponibilidade de pêssego para consumo in natura, ocupando atualmente cerca de $40 \%$ do mercado de consumo fresco dessa espécie (Byrne et al., 2012).

O cultivar Sunred, também chamado de 'Rubro-Sol', foi criado pelo programa de melhoramento da Universidade da Flórida, EUA, em 1964, e é altamente produtivo (de 25 a $40 \mathrm{~kg} /$ planta) e bem adaptado às condições da região sul do Brasil. Produz frutos de peso variável (50 a $80 \mathrm{~g}$ ) e com forma redondo-ovalada. Sua película apresenta de 90 a $100 \%$ de vermelho, sobre fundo amarelo, e a polpa é fundente, amarela, podendo ter traços de vermelho, semiaderente ao caroço e de sabor doce-ácido. A colheita inicia-se comumente na segunda ou terceira semana de novembro. Sua qualidade geral é regular (Raseira et al., 2014).
O cultivar 'Josefina' foi obtido pelo programa de melhoramento do Instituto Agronômico de Campinas (IAC), por meio de polinização livre, resultante do cruzamento entre o pessegueiro 'Ouromel' e a nectarineira 'Rubro- Sol', cujos frutos apresentam maturação precoce e epiderme bastante avermelhada (Ojima et al., 1986). De acordo com relatos de Matias et al., (2012), esse cultivar apresenta frutos com ângulo hue da casca de $93,46^{0}$ e cor da polpa de $78,43^{\circ}$, peso médio dos frutos de 40,42 g, diâmetro transversal de $42,32 \mathrm{~mm}$ e teor de sólidos solúveis de $12,27^{\circ}$ Brix.

As condições climáticas das regiões brasileiras produtoras de nectarina são muito variáveis, principalmente em relação à quantidade de frio necessário para superação da endodormência da espécie (Wagner Júnior $e t$ al., 2009). De acordo com Raseira et al. (2014), a nectarineira, assim como o pessegueiro, é uma fruteira de clima temperado, os mais importantes centros de produção comercial situam-se, por essa razão, entre as latitudes de 25 e $45^{\circ} \mathrm{N}$ e S. Em latitudes maiores, a temperatura mínima de inverno e as geadas de primavera são, usualmente, os fatores limitantes. Sob condições especiais, em altitudes elevadas, o cultivo pode, também, estender-se a regiões tropicais.

O conhecimento dos cultivares disponíveis e de sua adaptação aos locais de cultivo é extremamente importante, pois possibilita a escolha dos materiais com melhor potencial e adaptação (Modesto et al., 2014). Assim, este trabalho teve como objetivo avaliar a qualidade pós-colheita das nectarineiras 'Josefina' e 'RubroSol', cultivadas sob condições de clima subtropical, em Viçosa, MG.

\section{MATERIAL E MÉTODOS}

O estudo foi realizado, durante as safras de 2011, 2012 e 2013, com os cultivares de nectarina 'Josefina' e 'Rubro- Sol', cultivados no pomar experimental da Universidade Federal de Viçosa (UFV), Viçosa-MG ( $20^{\circ} 45^{\prime} \mathrm{S}$ e $42^{\circ} 51^{\prime} \mathrm{O}$; $649 \mathrm{~m}$ de altitude). A precipitação anual foi de 1322, 1362 e $1400 \mathrm{~mm}$, em 2011, 2012 e 2013, respectivamente, sendo dezembro e janeiro os meses mais chuvosos e julho o mais seco. A temperatura máxima média no mês mais quente foi de $30,9{ }^{\circ} \mathrm{C}$, em fevereiro de 2011, e no mês mais frio, a temperatura mínima média foi de $9,9^{\circ} \mathrm{C}$, em julho de 2011(Fonte: Estação Meteorológica da Universidade Federal de Viçosa, Viçosa-MG).

Após um ano de obtenção das mudas, quando estas apresentavam entre $25-30 \mathrm{~cm}$ de altura, elas foram enxertadas sobre o porta-enxerto 'Okinawa', sendo o plantio realizado em outubro de 2008, no espaçamento de 5,0 $\mathrm{m}$ entre linhas e 3,5 m entre plantas (572 plantas/ha), em área experimental de 0,2 ha. 
Durante a condução do experimento, foram realizadas práticas culturais e fitossanitárias, seguindo-se as recomendações técnicas da cultura. Foi utilizada cianamida hidrogenada, na dosagem de $0,8 \%$ e de $1 \%$ de óleo mineral, para a quebra de dormência das gemas. A solução foi aplicada na segunda semana de junho dos anos de 2011, 2012 e 2013, no estádio de gemas dormentes, por meio de pulverização. Realizaram-se podas de frutificação nos meses de maio e junho de cada safra e o raleio dos frutos foi realizado duas semanas após a plena floração.

Foram colhidos 30 frutos de cada cultivar, usandose como critério a mudança da coloração de fundo de verde para amarelo-claro ou branco-creme e avaliadas as características químicas e físicas descritas a seguir. A massa do fruto, em gramas (g), foi obtida com balança digital com precisão de $0,1 \mathrm{~g}$. O diâmetro longitudinal e o diâmetro transversal, em mm, foram medidos, utilizando-se paquímetro digital (marca Mitutoyo DL10). A firmeza da polpa, em Newton (N), foi determinada na região equatorial de uma das faces do fruto, após a remoção da epiderme, com penetrômetro digital Effe-Gi, modelo FT-011, ponteira de $8 \mathrm{~mm}$ de diâmetro. O teor de sólidos solúveis, expresso em ${ }^{\circ}$ Brix, foi analisado no suco retirado manualmente do fruto, por meio de refratômetro digital ATAGO (Palete PR101). A acidez titulável foi obtida por titulação com solução de $\mathrm{NaOH} 0,1 \mathrm{~N}$, expressando-se o resultado em percentagem de ácido málico. O teor de ácido ascórbico foi determinado por titulação com reagente de Tillman [2,6 diclorofenolindofenol (sal sódico) a 0,1\%], de acordo com metodologia descrita em AOAC (1997), e os resultados foram expressos em $\mathrm{mg}$ de ácido ascórbico por $100 \mathrm{~g}$ de polpa. Os carotenoides totais (CT) foram obtidos pelas equações de Lichtenthaler (1987), em $\mu \mathrm{gmL}^{-1}$ de extrato, a partir de leituras em espectrofotômetro nos comprimentos de onda de 470, 646,8 e $663,2 \eta \mathrm{m}$. Os resultados foram multiplicados por 25 e divididos pela massa de polpa, sendo expressos em mg/100g de polpa.

$\mathrm{O}$ experimento foi conduzido em esquema de parcelas subdivididas, no delineamento inteiramente casualizado, com seis repetições e três plantas úteis por parcela experimental, sendo que as parcelas corresponderam aos dois cultivares de nectarineira e, as subparcelas, aos três anos de avaliação, correspondentes aos ciclos agrícolas de 2011, 2012 e 2013. Com os resultados obtidos, determinou-se a média de cada cultivar para as características avaliadas. Os resultados foram submetidos à análise de variância e, as médias, comparadas pelo teste de Tukey, a 5\% de probabilidade. As análises foram realizadas com o auxílio do programa GENES (Cruz, 2013).

\section{RESULTADOS E DISCUSSÃO}

Na Tabela 1, são apresentadas as datas de colheita dos cultivares de nectarina, nas safras de 2011, 2012 e 2013. Houve uma variação de 13 e 9 dias nas datas de colheita, entre os anos, para 'Josefina' e 'Rubro- Sol', respectivamente. Toralles et al. (2008), avaliando características físicas e químicas de oito cultivares de pêssego em duas safras, relataram variação de oito dias no período de maturação do cultivar 'BR-6', e de 17 dias, no período de maturação do cultivar 'Jubileu'. Leonel \& Tecchio (2011), avaliando a produção e a sazonalidade de pessegueiro e nectarineira sob florescimento espontâneo e com cianamida hidrogenada e óleo mineral, durante duas safras, verificaram variação, no início da colheita da nectarina 'Sun Blaze', de 19 dias, de um ano para o outro, com aplicação de cianamida hidrogenada e óleo mineral.

Houve diferença significativa entre os cultivares quanto ao período entre o florescimento e colheita. Durante as três safras, o cultivar Rubro-Sol atingiu o pico de maturação em menor tempo, antecipando a colheita, em média, de 28,3 dias, em relação à do cultivar Josefina. Barbosa et al. (1990), avaliando a época e o ciclo de maturação de nectarinas, no Estado de São Paulo, verificaram um ciclo de maturação médio de 112 dias, caracterizando o cultivar como precoce. Resultado semelhante foi observado neste trabalho, com ciclo médio de 116,3 dias. Albuquerque et al. (2000) observaram nos cultivares Josefina e Rubro-Sol, cultivados na Zona da Mata mineira, um ciclo de maturação de 98,5 e 78 dias respectivamente. Neste trabalho, os cultivares Josefina e RubroSol podem ser classificados, quanto ao ciclo de maturação, em precoce e bem precoce, respectivamente.

$\mathrm{Na}$ Tabela 2, estão listadas as características físicas dos cultivares estudados, e o cultivar Josefina apresentou, na média dos três anos de avaliação, maior massa de fruto $(40,79 \mathrm{~g})$, entretanto não diferiu estatisticamente de 'Rubro-Sol'.

Em 2013, verificou-se que 'Josefina' produziu frutos com massa superior à dos frutos de 'Rubro- Sol'. Nos outros anos, não houve diferença estatística. Nienow \& Floss (2003), avaliando a produção de pessegueiro e nectarina no planalto médio do Rio Grande do Sul, encontraram, na média de três anos, massa de fruto de 67,1 e 64,97 g para as nectarinas 'Sunlite' e 'Linda', respectivamente.

Quanto aos diâmetros longitudinal e transversal, no ano de 2012, houve diferença entre os cultivares. Albuquerque et al. (2000), avaliando cultivares de pêssego e nectarina em Araponga, Minas Gerais, obtiveram valores de diâmetro transversal de 42,32 e 40,22 mm, para os cultivares 'Josefina' e 'Rubro- Sol', respectivamente, valores próximos às médias de três anos obtidas 
para os referidos cultivares, neste trabalho, de 41,59 e 40,01 mm. O tamanho dos frutos é determinado pelas características genéticas de cada cultivar e também influenciado por outros fatores de manejo no pomar (Giovanaz et al., 2014).

O cultivar 'Rubro- Sol' produziu frutos mais firmes nos três anos de avaliação, com média de 90,11 N, contra 50,78 $\mathrm{N}$ dos frutos de 'Josefina'. Houve variação na firmeza dos frutos entre os anos avaliados, sendo que no ano de 2011 observaram-se frutos mais firmes que em 2013, porém ambos semelhantes à firmeza dos frutos em 2012, o que desponta como potencial pós-colheita em relação a esta característica, uma vez que esta é uma importante característica física com implicações reológicas (Toralles et al., 2008), e segundo Wagner Júnior et al. (2011), a firmeza da polpa está relacionada com a resistência ao transporte e à vida de prateleira dos frutos, sendo fundamental a realização de estudos para se avaliar a qualidade dos frutos e para se adotar medidas de melhoramento e manutenção, de conformidade com os padrões de comercialização (Leite et al., 2010).

$\mathrm{Na}$ Tabela 3, encontram-se as características químicas dos cultivares estudados. Os teores de sólidos solúveis do cultivar Josefina foram significativamente superiores aos de 'Rubro-Sol', nas safras de 2012 e 2013, e seus frutos apresentaram menor acidez nos três anos de avaliação. Observou-se variação dos teores de acidez nos anos de avaliação e, essa alteração pode estar relaciona-

Tabela 1: Ciclo de maturação de dois cultivares de nectarina, cultivados no Sudeste do Brasil

\begin{tabular}{|c|c|c|c|c|}
\hline \multirow{2}{*}{ Cultivar } & \multicolumn{4}{|c|}{ Data de colheita } \\
\hline & 2011 & & 2012 & 2013 \\
\hline Josefina & 01 de novembro & & 19 de outubro & 28 de outubro \\
\hline Rubrosol & 29 de setembro & & 02 de outubro & 23 de setembro \\
\hline \multirow{2}{*}{ Cultivar } & \multicolumn{3}{|c|}{ Número de dias do florescimento à colheita } & \multirow{2}{*}{ Média } \\
\hline & 2011 & 2012 & 2013 & \\
\hline Josefina & 122 & 109 & 118 & $116,3 \mathrm{~A}$ \\
\hline Rubro- Sol & 89 & 92 & 83 & $88 \mathrm{~B}$ \\
\hline
\end{tabular}

Médias seguidas pela mesma letra nas colunas não diferem estatisticamente entre si, pelo teste de Tukey a 5\% de probabilidade.

Tabela 2: Massa, diâmetro longitudinal, diâmetro transversal e firmeza de polpa de frutos de dois cultivares de nectarina, cultivados no sudeste do Brasil

\begin{tabular}{|c|c|c|c|c|}
\hline \multirow{2}{*}{ Cultivares } & 2011 & 2012 & 2013 & \multirow{2}{*}{ Média } \\
\hline & \multicolumn{3}{|c|}{ Massa de fruto (g) } & \\
\hline Josefina & $40,42 \mathrm{Aa}$ & $35,56 \mathrm{Aa}$ & $46,40 \mathrm{Aa}$ & $40,79 \mathrm{a}$ \\
\hline Rubrosol & $36,03 \mathrm{Aa}$ & 43,86 Aa & $33,48 \mathrm{Ab}$ & 37,79 a \\
\hline Média & $38,23 \mathrm{~A}$ & $39,71 \mathrm{~A}$ & $39,94 \mathrm{~A}$ & \\
\hline CV (\%) Cultivar & 13,80 & $\mathrm{CV}(\%)$ ano & 9,94 & \\
\hline \multicolumn{5}{|c|}{ Diâmetro longitudinal (mm) } \\
\hline Josefina & $38,37 \mathrm{Aa}$ & $37,92 \mathrm{Ab}$ & $42,61 \mathrm{Aa}$ & $39,63 \mathrm{a}$ \\
\hline Rubrosol & $38,77 \mathrm{Aa}$ & $40,84 \mathrm{Aa}$ & $39,93 \mathrm{Aa}$ & $39,85 \mathrm{a}$ \\
\hline Média & $38,57 \mathrm{~A}$ & $39,38 \mathrm{~A}$ & $41,27 \mathrm{~A}$ & \\
\hline CV (\%) Cultivar & 5,13 & $\mathrm{CV}(\%)$ ano & 3,92 & \\
\hline \multicolumn{5}{|c|}{ Diâmetro transversal (mm) } \\
\hline Josefina & 42,07 Aa & $40,00 \mathrm{Ab}$ & $42,69 \mathrm{Aa}$ & $41,59 \mathrm{a}$ \\
\hline Rubrosol & $38,63 \mathrm{Ab}$ & $43,18 \mathrm{Aa}$ & $38,21 \mathrm{Ab}$ & $40,01 \mathrm{a}$ \\
\hline Média & $40,35 \mathrm{~A}$ & $41,59 \mathrm{~A}$ & $40,45 \mathrm{~A}$ & \\
\hline CV (\%) Cultivar & 4,07 & $\mathrm{CV}(\%)$ ano & 3,38 & \\
\hline \multicolumn{5}{|c|}{ Firmeza $(\mathrm{N})$} \\
\hline Josefina & $62,13 \mathrm{Ab}$ & $50,78 \mathrm{Bb}$ & $39,43 \mathrm{Cb}$ & $50,78 \mathrm{~b}$ \\
\hline Rubrosol & $95,66 \mathrm{Aa}$ & $90,11 \mathrm{Aa}$ & $84,55 \mathrm{Ba}$ & 90,11 a \\
\hline Média & $78,89 \mathrm{~A}$ & $70,44 \mathrm{AB}$ & $61,99 \mathrm{~B}$ & \\
\hline CV (\%) Cultivar & 12,09 & $\mathrm{CV}(\%)$ ano & 11,02 & \\
\hline
\end{tabular}

Médias seguidas pela mesma letra em maiúsculo na linha e, minúsculo na coluna não diferem entre si, pelo teste Tukey, a 5\%.

Rev. Ceres, Viçosa, v. 62, n.6, p. 621-626, nov-dez, 2015 
Tabela 3: Teor de sólidos solúveis, acidez titulável, teor de ácido ascórbico e teor de carotenoides de frutos de dois cultivares de nectarina, cultivados no sudeste do Brasil

\begin{tabular}{|c|c|c|c|c|}
\hline \multirow{2}{*}{ Cultivares } & 2011 & 2012 & 2013 & \multirow{2}{*}{ Média } \\
\hline & \multicolumn{3}{|c|}{ Teor de sólidos solúveis ( ${ }^{\circ}$ Brix $)$} & \\
\hline Josefina & $12,27 \mathrm{Aa}$ & $13,62 \mathrm{Aa}$ & $14,97 \mathrm{Aa}$ & $13,62 \mathrm{a}$ \\
\hline Rubrosol & $12,22 \mathrm{Aa}$ & $11,51 \mathrm{Ab}$ & $10,80 \mathrm{Ab}$ & $11,51 \mathrm{~b}$ \\
\hline Média & $12,24 \mathrm{~A}$ & $12,56 \mathrm{~A}$ & $12,89 \mathrm{~A}$ & \\
\hline CV (\%) Cultivar & 12,56 & $\mathrm{CV}(\%)$ ano & 4,18 & \\
\hline \multicolumn{5}{|c|}{ Acidez titulável (\%) } \\
\hline Josefina & $0,49 \mathrm{Ab}$ & $0,45 \mathrm{Ab}$ & $0,46 \mathrm{Ab}$ & $0,47 \mathrm{~b}$ \\
\hline Rubrosol & $1,27 \mathrm{Aa}$ & $1,10 \mathrm{Aa}$ & $1,03 \mathrm{Aa}$ & $1,13 \mathrm{a}$ \\
\hline Média & $0,88 \mathrm{~A}$ & $0,77 \mathrm{~B}$ & $0,74 \mathrm{~B}$ & \\
\hline CV (\%) Cultivar & 8,59 & $\mathrm{CV}(\%)$ ano & 8,54 & \\
\hline \multicolumn{5}{|c|}{ Teor de ácido ascórbico (mg.100g $\left.{ }^{-1}\right)$} \\
\hline Josefina & $8,17 \mathrm{Aa}$ & $9,51 \mathrm{Aa}$ & $6,83 \mathrm{a}$ & $8,17 \mathrm{a}$ \\
\hline Rubrosol & 7,90 Aa & $8,18 \mathrm{Ab}$ & $7,62 \mathrm{a}$ & $7,90 \mathrm{a}$ \\
\hline Média & $8,03 \mathrm{AB}$ & $8,84 \mathrm{~A}$ & $7,22 \mathrm{~B}$ & \\
\hline CV (\%) Cultivar & 12,33 & $\mathrm{CV}(\%)$ ano & 12,09 & \\
\hline \multicolumn{5}{|c|}{ Teor de carotenoides $\left(\mathrm{mg} .100 \mathrm{~g}^{-1}\right)$} \\
\hline Josefina & $0,12 \mathrm{Ab}$ & $0,49 \mathrm{Aa}$ & $0,32 \mathrm{Aa}$ & $0,31 \mathrm{a}$ \\
\hline Rubrosol & $0,37 \mathrm{Aa}$ & $0,43 \mathrm{Aa}$ & $0,38 \mathrm{Aa}$ & $0,39 \mathrm{a}$ \\
\hline Média & $0,24 \mathrm{~B}$ & $0,46 \mathrm{~A}$ & $0,35 \mathrm{AB}$ & \\
\hline CV (\%) Cultivar & 24,90 & $\mathrm{CV}(\%)$ ano & 25,22 & \\
\hline
\end{tabular}

Médias seguidas pela mesma letra em maiúsculo na linha e, minúsculo na coluna não diferem entre si, pelo teste Tukey, a 5\%.

da com o clima, uma vez que houve padronização do ponto de colheita para todos os anos avaliados. Todavia, para o teor de sólidos solúveis não houve alteração nos anos avaliados. Os frutos de 'Josefina' apresentam polpa branca e, de acordo com Silva et al. (2013), pêssegos de polpa branca tendem a apresentar maior teor de sólidos solúveis, enquanto pêssegos de polpa amarela, como as de 'Rubro- Sol', são geralmente mais ácidos. Gil et al. (2002), avaliando caraterísticas químicas em frutos de pêssegos e nectarinas, observaram maior acidez titulável e menor $\mathrm{pH}$ em frutos de polpa amarela do que em frutos de polpa branca, em ambos os casos.

Quanto ao teor de ácido ascórbico, houve diferença significativa entre os cultivares apenas no ano de 2012, com valores variando de 6,83 a 9,51 mg/100 g, para 'Josefina', em 2013 e 2012, respectivamente. Segantini et al. (2012) caracterizaram polpa de pêssegos produzidos em São Manuel, SP, e relataram valores de vitamina C entre 7,95 e 17,31 mg/100 g, nos cultivares de pêssego de polpa amarela avaliados. De acordo com os mesmos autores, os teores de vitamina $\mathrm{C}$ podem variar em função de outros fatores, como tratos culturais e diferentes locais de cultivo.

A nectarina 'Rubro-Sol' apresentou teor de carotenoides estatisticamente superior ao de 'Josefina,' apenas em 2011. Este fato pode estar relacionado com a cor da polpa, uma vez que Costa et al. (2010) concluí- ram que a concentração dos teores de carotenoides totais caracteriza a coloração amarela da polpa de ciriguelas, confirmada por meio da análise colorimétrica e que, de acordo com Gama \& Sylos (2005), as variações de cor da polpa de frutos, observadas entre as variedades, são devidas às flutuações da quantidade dos diferentes carotenoides, podendo variar com as condições climáticas de cada safra, o que foi observado neste trabalho.

\section{CONCLUSÕES}

O cultivar 'Rubro-Sol' destacou-se por apresentar frutos com polpa mais firme.

O cultivar 'Josefina' destacou-se por apresentar frutos com maior teor de sólidos solúveis e menor acidez.

\section{AGRADECIMENTOS}

Ao CNPq, CAPES e FAPEMIG pelo apoio financeiro.

\section{REFERÊNCIAS}

Albuquerque AS, Bruckner CH, Cruz CD \& Salomão LCC (2000) Avaliação de cultivares de pêssego e nectarina em Araponga, Minas Gerais. Revista Ceres, 47:401- 410 .

AOAC - Association of the Official Analytical Chemists International (1997) Official methods of analysis of the Association of the Official Analytical Chemists International. 16 ${ }^{\mathrm{a}}$ ed. Washinghton, Patricia Cunniff. 1170p.

Rev. Ceres, Viçosa, v. 62, n.6, p. 621-626, nov-dez, 2015 
Barbosa W, Ojima M, Dall'orto FAC \& Martins FP (1990) Época e ciclo de maturação de pêssegos e nectarinas no estado de São Paulo. Bragantia, 49:221-226.

Byrne DH, Raseira MB, Bassi D, Piagnani C, Gasic K, Reighard GL, Moreno MA \& Pérez S (2012) Peach. In: Badenes ML \& Byrne DH (Eds.) Fruit breeding. New York, Springer Science. p.505-569.

Costa MGP, Figueiredo FJ, Silva QJ \& Lima VLAG (2010) Carotenóides totais e caracterização cromática de polpas de frutos de genótipos de cirigueleiras cultivadas no banco de germoplasma do IPA. In: $10^{\mathrm{a}}$ Jornada de Ensino, Pesquisa e Extensão, Recife. Anais, UFRPE. CDROM.

Cruz CD (2013) Genes - a software package for analysis in experimental statistics and quantitative genetics. Acta Scientiarum Agronomy, 3:271-276.

Gama JJT \& Sylos CM (2005) Major carotenoid composition of Brazilian Valencia Orange juice: identification and quantification by HPLC. Food Research International, 38:899-903.

Gil MI, Tomas-Barberan FA, Hess-Pierce B \& Kader AA (2002) Antioxidant capacities, phenolic compounds, carotenoids, and vitamin $\mathrm{C}$ contents of nectarine, peach, and plum cultivars from California. Journal of Agricultural and Food Chemistry, 50:4976-4982.

Giovanaz MA, Fachinello JC, Goulart C, Radünz AL, Amaral PA \& Weber D (2014) Produção e qualidade de pêssegos, cv. Jubileu,com uso de fitorreguladores. Revista Ceres, 61:552-557.

Leite GA, Medeiros EV de, Mendonça V, Moraes PLD de, Lima LM de \& Xavier IF (2010) Qualidade pós-colheita da banana 'Pacovan' comercializada em diferentes estabelecimentos no município de Mossoró-RN. Revista Brasileira de Ciências Agrárias, 5:322-327.

Leonel S, Leonel M \& Tecchio MA (2014) Fruit quality in the peach and nectarine with application of hydrogenated cyanamide and mineral oil. Revista Ciência Agronômica, 45:581-587.

Leonel S \& Tecchio M (2011) Produção e sazonalidade de pessegueiro e nectarineira sob florescimento espontâneo e com cianamida hidrogenada e óleo mineral. Revista Brasileira de Fruticultura, 33:227234.

Leonel S, Pierozzi CG \& Tecchio MA (2011) Produção e qualidade dos frutos de pessegueiro e nectarineira em clima subtropical do estado de São Paulo. Revista Brasileira de Fruticultura, 33:118-128.
Lichtenthaler HK (1987) Chlorophylls and carotenoids: Pigments of photosynthetic biomembranes. Methods in Enzymology, 148:349382.

Matias RGP, Silva DFP, Silva JOC, Ribeiro MR, Oliveira SP \& Bruckner CH (2012) Caracterização física e química de três cultivares de nectarina na Zona da Mata de Minas Gerais. Revista Brasileira de Agricultura Sustentável, 2:60-64.

Modesto JH, Vedoato BTF, Leonel S \& Techio MA (2014) Crescimento vegetativo, fenologia, produção e sazonalidade dos frutos de pessegueiros e nectarineira. Revista Magistra, 26:425-430.

Nienow AA \& Floss LG (2003) Produção de pessegueiro e nectarina no planalto médio do rio Grande do Sul em anos de inverno ameno. Ciência Rural, 33:241-246.

Ojima M, Campo Dall'Orto FA, Barbosa W, Tombolato AFC, Martins FP \& Rigitano O (1986) Josefina: nova nectarina de polpa branca. Sociedade Brasileira de Fruticultura. 2:417-419.

Ramos DP \& Leonel S (2008) Características dos frutos de cultivares de pessegueiros e de nectarineira, com potencial de cultivo em Botucatu, SP. Bioscience Journal, 24:10-18.

Raseira MB, Pereira JFM \& Carvalho FLC (2014) Pessegueiro. Brasília, Embrapa. 776p.

Segantini DM, Leonel S, Lima SMC \& Ramos ARP (2012) Caracterização da polpa de pêssegos produzidos em São Manuel-SP. Ciência Rural, 42:52-57.

Silva DFP, Silva JOC, Matias RGP, Ribeiro MR \& Bruckner CH (2013) Correlação entre características quantitativas e qualitativas de frutos de pessegueiros na geração $\mathrm{F}_{2}$ cultivadas em região subtropical. Revista Ceres, 60:53-58.

Toralles RT, Vendruscolo JL, Malgarim BM, Cantilhano RF, Schunemann APP \& Antunes PL (2008) Características físicas e químicas de cultivares brasileiras de pêssegos em duas safras. Revista Brasileira Agrociência, 14:327-338.

Wagner Júnior A, Bruckner CH, Cantín MC, Sánchez MAM \& Santos CEM (2011) Seleção de progênies e genitores de pessegueiro com base nas características dos frutos. Revista Brasileira de Fruticultura, 33:170-179.

Wagner Júnior A, Bruckner CH, Salomão LCC, Pimentel LD, Silva JOC \& Santos CEM (2009) Avaliação da necessidade de frio de pessegueiro por meio de ramos enxertados. Revista Brasileira de Fruticultura, 31:1054-1059. 